\title{
Article
}

\section{Eating well, living well and weight management: A co-produced semi- qualitative study of barriers and facilitators experienced by adults with intellectual disabilities}

Doherty, Alison Jayne, Jones, Stephanie, Chauhan, Umesh and Gibson, Josephine

Available at http://clok.uclan.ac.uk/22791/

Doherty, Alison Jayne ORCID: 0000-0003-3593-8069, Jones, Stephanie ORCID: 0000-0001-9149-8606, Chauhan, Umesh ORCID: 0000-0002-0747-591X and Gibson, Josephine ORCID: 0000-0002-3051-1237 (2020) Eating well, living well and weight management: A co-produced semi-qualitative study of barriers and facilitators experienced by adults with intellectual disabilities. Journal of Intellectual Disabilities, 24 (2). pp. 158-176. ISSN 1744-6295

It is advisable to refer to the publisher's version if you intend to cite from the work. http://dx.doi.org/10.1177/1744629518773938

For more information about UCLan's research in this area go to http://www.uclan.ac.uk/researchgroups/ and search for <name of research Group>.

For information about Research generally at UCLan please go to http://www.uclan.ac.uk/research/

All outputs in CLoK are protected by Intellectual Property Rights law, including Copyright law. Copyright, IPR and Moral Rights for the works on this site are retained by the individual authors and/or other copyright owners. Terms and conditions for use of this material are defined in the policies page. 


\section{Eating well, living well and weight management: A co-produced semi- qualitative study of barriers and facilitators experienced by adults with intellectual disabilities}

\section{Accessible summary}

- People with intellectual disabilities took part in research to find out what helps or hinders them from eating well, living well and managing their weight.

- They said carers' support helps, but carers need training.

- They said they need clear and accessible information about healthy lifestyles.

- They said they are frustrated by the difficulties they face in trying to eat well, live well and manage their weight, if they want to.

\section{Introduction}

Obesity is defined as a Body Mass Index (BMI) $\geq 30$ (NICE, 2014). Adults with intellectual disabilities in England are more likely to be obese than their non-disabled peers (NHS Digital, 2017). Obesity affects $46 \%$ of female and $32 \%$ of male adult patients with intellectual disabilities who are registered with primary health care in England and who have had a BMI check, compared to $30 \%$ of female and male adult patients without intellectual disabilities (NHS Digital, 2017). Adults with intellectual disabilities who are obese are more at risk of experiencing serious obesity-related conditions such as coronary heart disease, stroke and type 2 diabetes than adults without intellectual disabilities (Melville et al., 2008; Public Health England, 2015; NHS Digital 2017).

Reasons for the high prevalence of obesity amongst this population are complex (Taggart and Cousins, 2014). Contributing factors may include poverty, poor nutrition, genetics, medication, poor dietary habits, very high levels of physical inactivity, and overfeeding by 
carers or support workers to prevent boredom or conflict (Emerson, 2003; Rimmer and Yamaki, 2006; McGuire, Daly and Smyth, 2007; Melville et al., 2007; Matthews et al., 2011). Adults with intellectual disabilities may be unable to access activities and services to help them eat well, live well and manage their weight because of limited support, restrictions to personal income, inaccessible services or activities, as well as carers' issues and concerns (Messent, Cooke and Long, 1998; Hatton, Roberts and Baines, 2011; Spanos et al., 2013a; Spanos et al., 2013b; Spanos et al., 2014; Sundblom, Bergstrom and Elinder, 2015; Cartwright et al., 2017). Some adults with intellectual disabilities may lack motivation to manage their own weight and they may need motivation from others such as carers, support workers or health care practitioners to manage their diet and physical activity or both (Spanos et al., 2013a; Spanos et al., 2013b; Spanos et al., 2014; Sundblom, Bergstrom and Elinder, 2015; Cartwright et al., 2017). Some individuals with intellectual disabilities may also have physical disabilities and have difficulty leaving their accommodation, and some carers and or support workers may not support individuals' participation in physical activity programmes, and so sedentary activities and a culture of `staying-in’ may become a dominant activity (Messent, Cooke and Long, 1998; Horvat and Franklin, 2001; Frey, Buchanan and RosserSandt, 2005). Individuals with intellectual disabilities may also face barriers to accessing health care services, such as problems with communication, a lack of support to facilitate access, discriminatory attitudes, and failure by health service providers to make `reasonable adjustments' to meet their needs (Hatton, Roberts and Baines, 2011; Taggart, 2014).

Reviews of weight management interventions for adults with intellectual disabilities who are obese have found a lack of evidence-based interventions for this population and a lack of controlled trials and qualitative research in this field (Spanos et al., 2013a; Doherty et al., 2017). Furthermore, the studies identified did not fully explore participants' perceptions of the interventions or explain the theoretical basis for the studies' interventions (Spanos et al., 
2013a; Doherty et al., 2017). Historically, research involving people with intellectual disabilities has mainly focused on measuring the efficacy of interventions aimed at modifying their behaviour (Craig \& Bigby, 2015; Simons \& Watson, 2015). Research has been done to, rather than with, this population (Duckett \& Fryer, 1998; Walmsley, 2001; Gates \& Waight, 2007; Nind \& Vinha, 2012; Chapman, 2013; Simons \& Watson, 2015; Brown et al., 2017). Gaining a better understanding of the day-to-day lives of people with intellectual disabilities may inform policies and practices so that they are treated as they desire to be treated (McDonald, Kidney and Patka, 2013). People with intellectual disabilities need to be active participants in research concerning the development of interventions that affect their health and well-being i.e. 'Nothing about us, without us' (Stack and McDonald, 2014).

This study used inclusive research principles to try to reduce or mitigate against some of the challenges experienced by other researchers who have conducted research involving this population - such as challenges obtaining ethical approval and consent for this population (Nicholson, Colyer and Cooper, 2013); focus group problems involving this population (Nind, 2008; Kaehne and O'Connell, 2010); unresponsiveness and communication issues (Booth and Booth, 1996). Inclusive research principles adopted by this study included coproduction. Co-production in research aims to instil principles of empowerment in practice by actively working with individuals and communities (such as people with intellectual disabilities) and facilitating their greater control over the research process (Collins and Evans, 2002). Co-production has emerged as a potential solution to criticisms that research is often conducted which fails to engage people in issues of concern to them (Collins and Evans, 2002). Advocates of co-produced research argue that research is enhanced through individuals' or communities' 'experiential expertise' as their involvement may highlight relevant issues which may be otherwise neglected by so-called research 'experts' (Collins and Evans, 2002). Research that is co-produced may shed light on barriers and facilitators 
involved in weight management for this population and may help develop potential theories and solutions to identified barriers.

\section{Study aim}

The aim of this study was to use co-production methods to explore the views and experiences of adults with intellectual disabilities in relation to barriers and facilitators to eating well, living well (such as access to adequate income and living conditions), and to managing their weight, if they want to.*

* the premise here being that people with intellectual disabilities should be afforded the same choices in life as their non-disabled peers.

\section{Objectives}

The objectives of the research were to explore:

(a) What may help or may make it difficult for people to eat well and live well from the perspectives of adults with intellectual disabilities.

(b) Barriers and facilitators to weight management interventions from the perspectives of adults with intellectual disabilities who want to manage their weight.

\section{Approach}

A self-advocacy group involving adults with intellectual disabilities and their carers in the North West of England was approached by the lead researcher and asked whether they thought this topic and co-produced research on this topic was relevant, interesting and of concern to them and to others with intellectual disabilities. A unanimous positive response was received and two adults with intellectual disabilities from the self-advocacy group volunteered to advise on the research methods, questions, materials and recruitment of participants. 


\section{Methods}

Small focus groups were chosen for this study in line with the preferences of the selfadvocacy group, who stated that people with intellectual disabilities are better supported in smaller facilitated focus groups rather than in individual interviews or larger focus groups. Available evidence also suggests that people with intellectual disabilities can be better supported in small focus groups which are facilitated by a skilled facilitator who is familiar with the participants' communication (Fraser and Fraser, 2001).

\section{Materials}

Advisors from the self-advocacy group worked with the lead researcher to co-produce recruitment materials including easy-read letters to potential participants, participant information sheets, and consent forms. These are the types of tasks that people with intellectual disabilities commonly undertake within a co-produced or inclusive research project. The lead researcher supplied the advisors with draft outline information for the recruitment materials and also for the focus group materials. The advisors then adapted this outline information to create easy-read accessible formats using simple words and pictures. Materials were finalised with the lead researcher and some minor amendments were provided by the advisors. Bespoke easy-read focus group materials, including a study topic guide comprising a questionnaire and worksheet (appendix 1) were co-produced by the advisors and the lead researcher to elicit responses from focus group participants. The easy-read questionnaires provided space for individual participants to provide detailed information on some, or all, of the research questions, if they wanted to. The easy-read worksheets were a single sheet of A4 designed so that individual participants could write familiar words or draw pictures to represent their responses. Advisors were paid for their involvement in the coproduced study. 


\section{Ethics}

The study was approved by the ethical committee at the host academic institution. Advisors from the self-advocacy group helped with the ethics process by ensuring the needs of people with intellectual disabilities were met by the research e.g. availability of easy-read materials such as easy-read consent forms to gain informed consent, easy-read participant information sheets and ensuring the availability of optional support from carers or support workers during the focus groups.

\section{Recruitment}

Convenience sampling was used to recruit adults with intellectual disabilities (aged 18 years and over) to the study. The participants were all recruited from an existing North-West England Regional Forum for people with intellectual disabilities by the same self-advocacy group for people with intellectual disabilities that had advised on the research study and that had supplied advisors. Having a self-advocacy group to assist with the recruitment of participants for this study aided the recruitment process. The existing Regional Forum was organised and facilitated by representatives from the self-advocacy group. Participants involved in the Forum were self-identified as having mild-to-moderate intellectual disabilities. Some participants also self-identified as having physical disabilities as well. People involved in the Forum were invited by the self-advocacy group to participate in the study using the co-produced easy-read covering letters and participant information sheets. The potential participants from the Forum received a week's advanced notification of the date of the Forum meeting and the study. On the day of the actual Forum, after the normal business of the Forum, the lead researcher was introduced to people attending the Forum by the chair of the self-advocacy group. The lead researcher then introduced the study and there was an opportunity for questions about the study. Potential participants questioned whether their carers or support workers could stay to support them in the focus groups and how they 
would be advised of the research findings. The potential participants were advised by the lead researcher that their carers or support workers could support them in the focus groups if they wished and that an easy-read report to inform them of findings would be made available to them at the end of the study. It was made clear that participation in the study was not compulsory just because they had attended the Forum.

All 19 adults with intellectual disabilities (13 men and 6 women) involved in the Forum elected to take part in the study and they all provided informed written consent using the coproduced easy-read consent forms. The mean age of the participants who supplied agerelated information ( $\mathrm{n}=13$ ) was 45 years (range 32 to 57$)$. The participants were supported by 8 of their carers or support workers (4 men and 4 women).

\section{Data collection}

Four focus groups and one wider group discussion (involving all four focus groups) were held after the Forum's routine business meeting in September 2016 in a venue which was familiar to all participants. The focus groups (comprising an average of 4 participants with intellectual disabilities per focus group) were facilitated by skilled paid facilitators from the self-advocacy group for people with intellectual disabilities who had experience of working with this population and who were known to participants. The four focus groups ran concurrently for 45 minutes, followed by a 15-minute wider group discussion involving all participants of all four focus groups, their carers or support workers, the facilitators and the lead researcher. Participants, carers, support workers and facilitators were paid a one-off fee for their involvement in the study.

Participants were supported to complete the questionnaires and worksheets by the facilitators, lead researcher and by their carers or support workers. 14 completed questionnaires and 17 completed worksheets were handed back to the lead researcher at the end of the focus groups. 
Participants provided responses for all parts of the completed questionnaires and worksheets that were handed in. However, two participants chose not to hand back either a completed questionnaire or a completed worksheet to the lead researcher. A further three participants chose only to complete and hand back a completed worksheet.

\section{Data analysis}

Data was analysed by the lead researcher using a staged process for conducting thematic analysis (Braun and Clarke, 2006), and by use of a thematic network analysis tool (AttrideStirling, 2001). During stage one of the thematic analysis, participants' individual responses from the worksheets, questionnaires and group discussion were transcribed and transferred onto Excel spread-sheets by the lead researcher. During stage two, transcripts and spreadsheets were read and re-read by the lead researcher to explore any emerging issues and patterns of meaning. Stage three involved the lead researcher exploring potential codes and ideas from the individual transcripts and spread-sheets. Stage four began when a list of ideas about what was in the data and what was interesting about them was generated. Coding was first done by hand and then using NVivo v11 computer software by the lead researcher. As many patterns or themes as possible were noted. Stage five involved sorting codes into themes. A coding framework was devised by the lead researcher as part of the analysis process to reduce the collective text into coded segments and themes. Basic themes abstracted from the coded segments were refined and further re-refined and assessed to explore if there were any global themes arising. A thematic network 'map' was also developed as part of the analysis to visually illustrate themes and the relationships between these themes (appendix 2). These themes were reviewed during stage six of the thematic analysis. The data analysis process involved constantly referring to the data for evidence to support the emerging codes and themes and their interconnections. During stages seven and eight, the lead researcher explored the substance of each emerging theme and a 'story' of the 
data was described using data extracts from respondents to validate the analysis and put forward an argument for the research findings. The validity and dependability of the analysis was assessed through regular discussion with the research team and through re-examining data analysis documentation to ensure findings were supported.

A flowchart summarising stages of the study is provided (Figure 1).

An easy-read report of findings and a creative visual summary of findings were co-produced by the advisors at the end of the study from data supplied by the lead researcher. The report and visual summary were shared with participants at the end of the analysis for validation and feedback purposes. No further comments were received and no changes were requested. 


\section{Figure 1: Flow-chart summarising stages of the study}

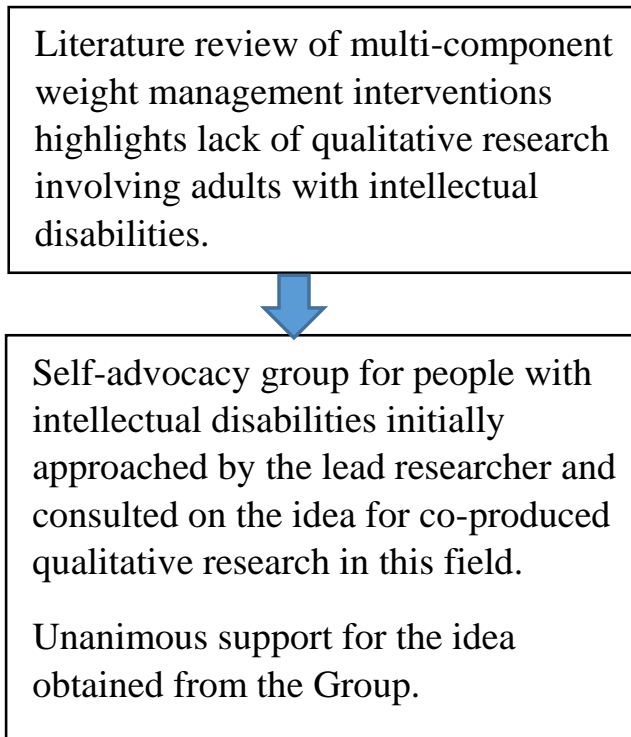

Advisors from the self-advocacy group and the lead researcher coproduce research questions, methods and materials.

Self-advocacy group representatives advise on recruitment of participants.
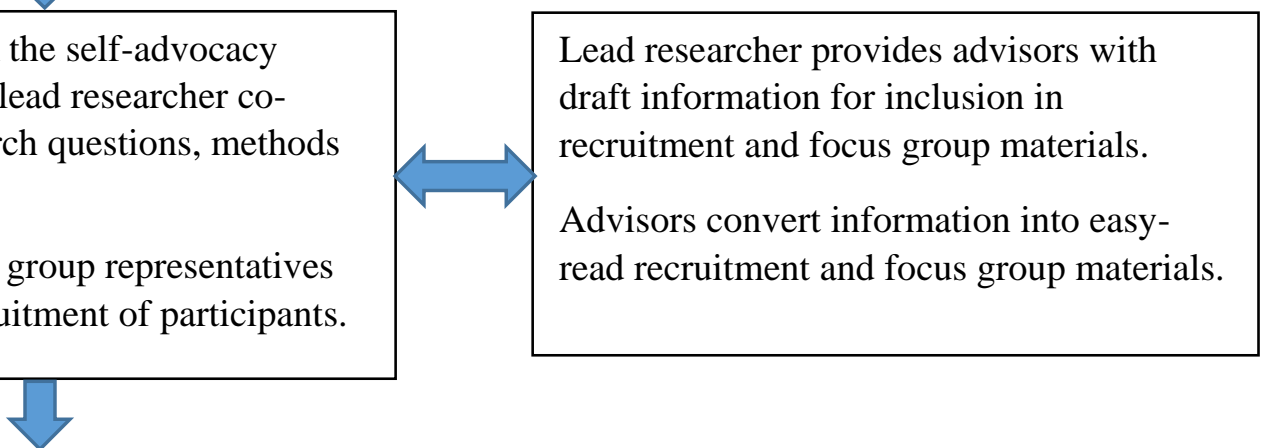

Ethical approval for study sought and granted by the host academic institution.

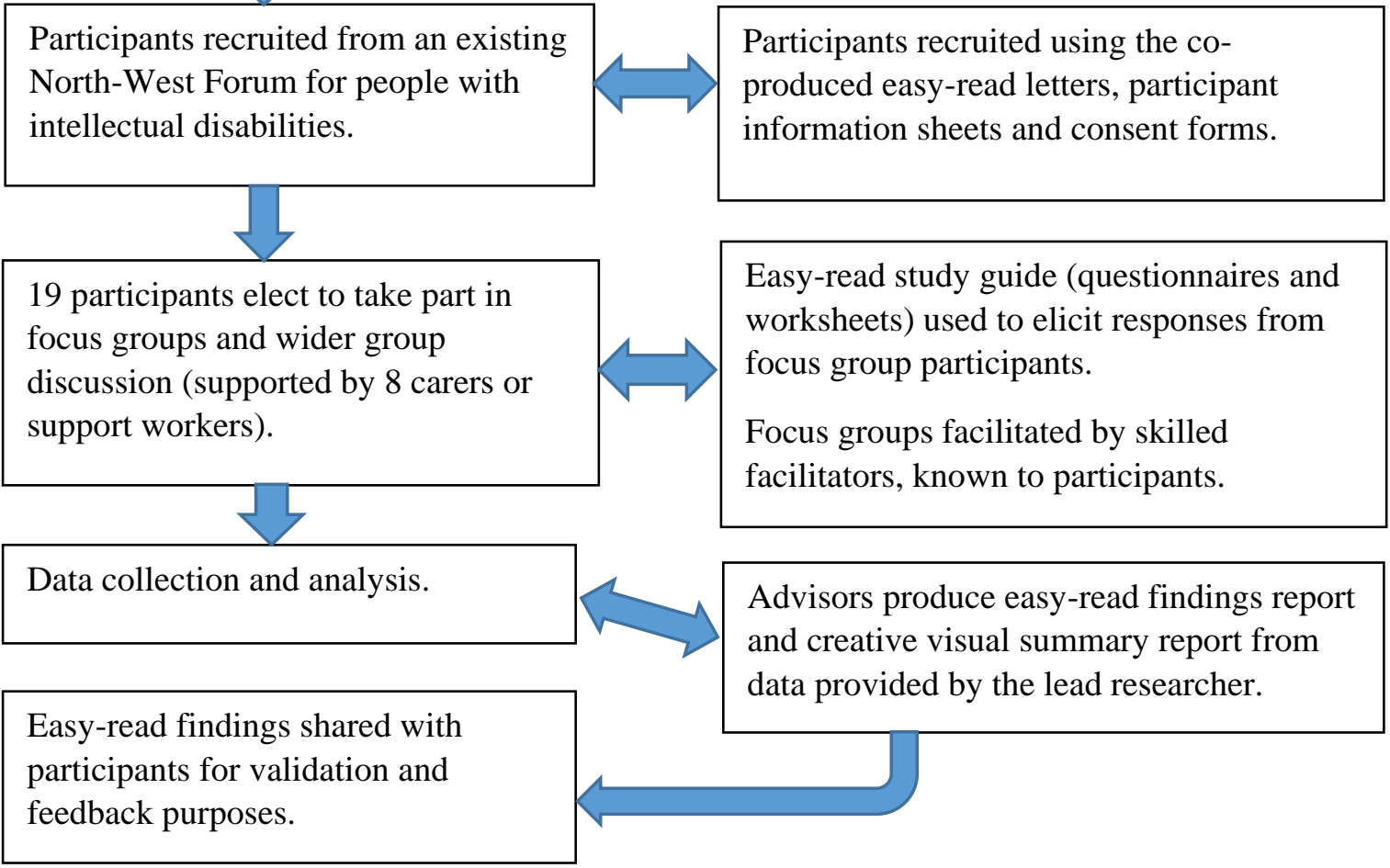




\section{Findings}

Six themes arose from the analysis of the data gathered from the worksheets, questionnaires and wider group discussion. These are discussed below:

\section{Caring support}

Participants indicated the importance of having support from carers and or support workers to help them with every-day tasks such as shopping and with accessing regular groups and activities to help them eat well, live well and manage their weight if they wanted to:

“Support to buy shopping." (Participant 12)

“Having support to take part in groups.” (Participant 11)

However, some participants indicated that the support they needed to help them was not always available and some participants therefore did not always have opportunities to get out of their house:

"Don't always have the support to get out." (Participant 8)

\section{Group support}

Participants commented on the value of support from others such as those involved in weight management groups with similar weight loss goals:

"I found [name of a commercial weight management service] helpful." (Participant 1)

"Going to [name of a commercial weight management service]. Some of the staff are very supportive of me." (Participant 10)

"Motivation and encouragement from the group." (Participant 10)

"Having people who wanted the same as me." (Participant 3)

Participants expressed a desire to be matched with other people who enjoyed the same interests as them so they could be routinely taken to activities they enjoyed:

"Buddies - other people who want to enjoy the same things as me like the rugby-so I can always get there." (Participant 13) 


\section{Better, clearer, accessible information and training}

Participants cited the need for better, clearer and more accessible healthy lifestyle information. Some participants were unable to obtain accessible information; others had received conflicting information:

“Information in easy read.” (Participant 9)

“[There is] No easy read.” (Participant 12)

"Not sure what to eat. What is healthy?" (Participant 6)

"Good information [needed] on how to be healthy." (Participant 7)

“GP said I needed to lose weight but did not offer any help." (Participant 11)

"Have seen a dietician. Not very helpful. Gave me wrong information." (Participant 2)

Participants also felt that carers and support workers required training so they could better support people with intellectual disabilities to eat well, live well and manage their weight:

"Support workers - training to be able to support people correctly in cooking, eating, exercise." (Participant 12)

“Support workers need to be trained up.” (Participant 4)

\section{Money}

Participants expressed concerns about having sufficient personal income to pay for the routine support they needed, to buy the right kinds of foods, and to routinely attend activities:

"I make sure I have enough money." (Participant 5)

"Not having money to buy the right food." (Participant 14)

"What happens if funding is lost?" (Participant 12)

\section{Recognition of health and weight concerns by self and by others}

Of those 14 participants who returned completed questionnaires, 10 expressed concerns about their own health and some participants listed medical conditions including high blood pressure, leukaemia, and problems with mobility. 9 of these 14 participants also expressed 
concerns about their weight. However, 5 of these 9 participants indicated in their

questionnaire responses and in the wider group discussions that they were unable to access appropriate support to deal with their weight concerns:

"I'd like to join [name of a commercial weight management service] but no support to go and too expensive." (Participant 11)

Those that expressed a desire to lose weight spoke about a lack of support and a lack of money which had prevented them accessing weight management services. However, some participants stated that they had been supported to attend a commercial weight management service. One participant who stated that he had been supported to attend a commercial weight management service had received a 'Slimmer of the Year' award for losing 30kgs in weight. None of the participants who wanted to lose weight (or who had lost weight) could recall being referred by their GP or any other health care practitioner to any commercial or non-commercial weight management services. Those that had accessed such services said that they had either self-referred or they had been helped by their carer or support worker to attend them.

\section{External barriers}

Participants in the wider group discussion stated that they found it difficult to access sports, leisure and recreational services as some of these were not adapted to meet their intellectual disabilities. Some participants also had physical disabilities as well as intellectual disabilities and stated that they had experienced further difficulties with accessing such services because of this. Participants in the wider group discussion also voiced their frustration over the advertising of less healthy foodstuffs on television during the recent Paralympics. They commented about the general widespread availability and marketing of less healthy fast-food, takeaways and convenience foods over more healthy foodstuffs and they found it difficult to eat well due to issues such as confusing food labelling:

\section{"Understanding the tables and conflicting information" (Participant 13)}


Consequently, because of all these barriers under all the themes, they felt that it was often:

"Easier to get a takeaway delivered." (Participant 12)

An overarching theme of frustration emerged from analysis of participants' responses.

Participants expressed frustrations - in their individual responses, in their focus groups and in the wider group discussions - over barriers including restrictions to personal incomes, difficulties obtaining consistent caring support, inaccessible activities and services, external barriers, and a lack of clear and accessible information on how to eat well and live well and why this was important.

14 participants provided suggestions (in their questionnaires and worksheets) for how the overall health and wellbeing of people who have intellectual disabilities could be improved (Figure 2). Their suggestions emphasise their need for greater awareness, understanding, support, training and for better, clearer, accessible information on healthy lifestyles. 
Figure 2: Participants' perceptions of what can be done to improve the health and wellbeing of people with intellectual disabilities (gathered from their completed questionnaires and worksheets)

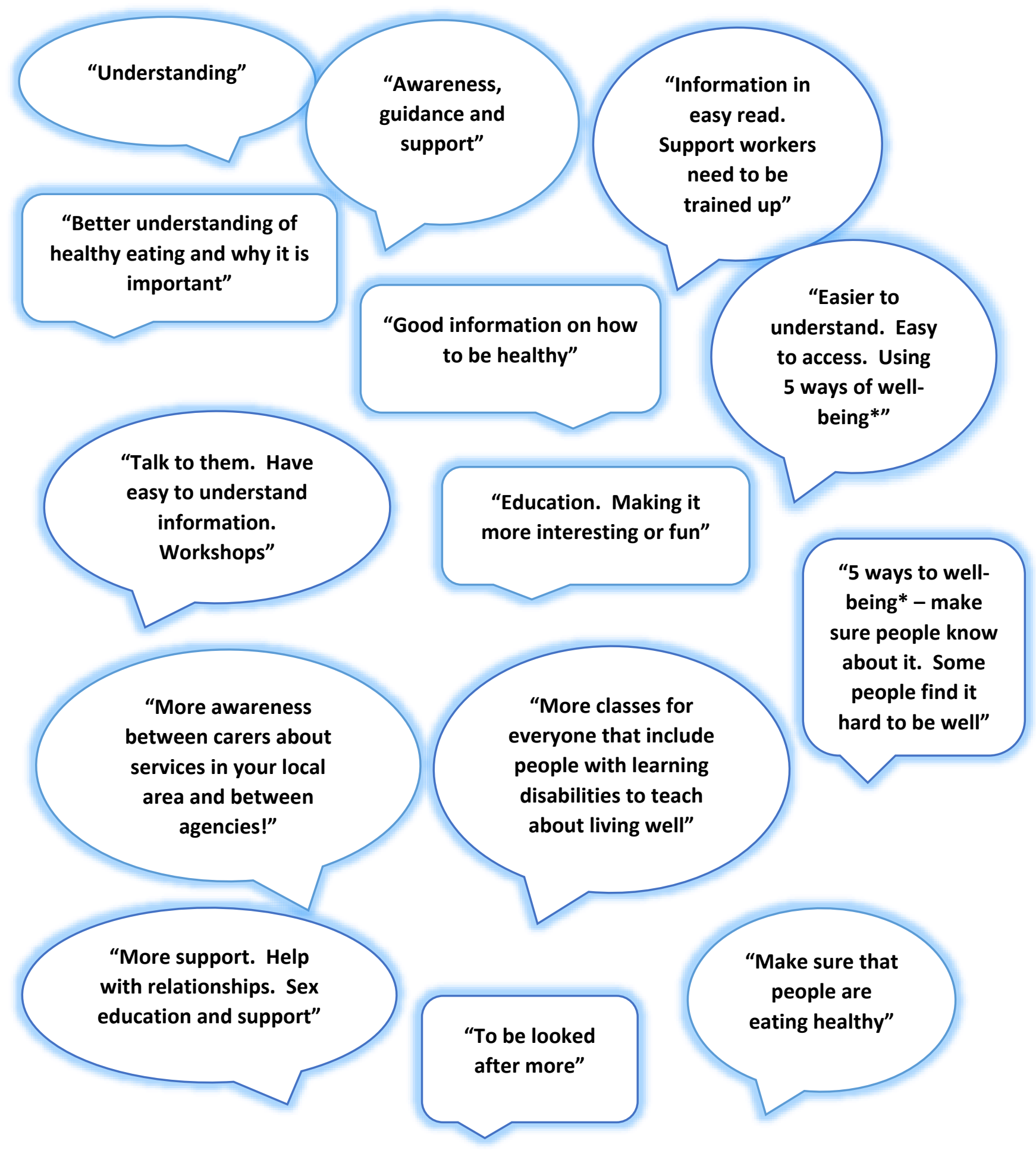

*5 ways to wellbeing: sets out 5 recommended actions to improve personal wellbeing: (1) connect, (2) be active, (3) take notice, (4) keep learning, (5) give: https://www.gov.uk/government/publications/five-ways-to-mental-wellbeing 


\section{Discussion}

The higher prevalence of obesity in adults with intellectual disabilities than in their nondisabled peers, and the associated health risks, represent a health inequality concern for this population (Rimmer and Yamaki, 2006; Melville et al., 2008). However, there is a lack of research involving adults with intellectual disabilities in this field (Spanos et al., 2013a; Doherty et al., 2017). This study involved adults with intellectual disabilities in a coproduction process to explore their views and experiences of barriers and facilitators to eating well, living well and managing their weight. The study found that adults with intellectual disabilities experience several barriers to eating well, living well and managing their weight including: problems accessing routine caring support; a lack of clear and accessible healthy lifestyle information; unmet training needs for carers and support workers; personal income restrictions; and external barriers such as inaccessible services and the widespread marketing and availability of less healthy foodstuffs. Other studies have found similar barriers which support this study's findings (Messent, Cooke and Long, 1998; Spanos et al., 2013a; Spanos et al., 2013b; Sundblom et al., 2015; Cartwright et al., 2017). However, none of these previous studies were co-produced by adults with intellectual disabilities and, whilst two studies had asked participants for their views of barriers to physical exercise (Messent, Cooke and Long, 1998; Cartwright et al., 2017), none asked participants for their views and experiences of barriers and facilitators to eating well, living well and weight management interventions.

Most participants in this co-produced study had health and weight concerns but they were frustrated because they were unable to access the necessary support and resources to help them deal with their concerns. None of the study's participants who had weight concerns could recall being referred to weight management services by their doctor or any other health care practitioner. Those who had accessed services had either self-referred or they had been 
helped by their carer or support worker. These participants had accessed commercial services which they stated were expensive. At the time of writing, the costs of the commercial weight management services used by the participants were between $£ 9.95$ and $£ 10.70$ for an initial joining fee, with further payments of between $£ 4.95$ to $£ 6.25$ per weekly meeting. Therefore, there may be a general lack of awareness of the availability of non-commercial weight management services commissioned by local authorities which are free to those with obesity who are referred by their doctor (or other health care practitioners), or there may be problems with referral processes or access issues. Primary health care practitioners may not routinely refer adults with intellectual disabilities who want to manage their weight to these services as they may not be aware of the availability of these services or they perceive such services to be unsuitable for the needs of this population. Also, whilst some studies suggest that health care practitioners have positive attitudes towards people with intellectual disabilities (Melville et al, 2005), some other studies suggest stigmatising attitudes may influence their treatment of this population and that these attitudes may result in inequity of access to health care services for people with intellectual disabilities (Pelleboer-Gunnick et al., 2017). Providers of weight management services also need to ensure that their services are accessible and tailored to accommodate the needs of this population, some of whom may have physical, as well as intellectual, disabilities. Further co-produced research involving adults with intellectual disabilities may usefully explore the inclusivity of existing commercial and non-commercial weight management services (including referral processes, equity of access and delivery issues) for adults with intellectual (and physical) disabilities.

Previous studies of evidence-based weight management interventions for adults with intellectual disabilities have identified the need for participants to be motivated to manage their weight, and that others (e.g. carers and staff involved in the delivery of interventions) also needed to be motivated to support them (Spanos et al., 2013b; Spanos et al, 2014; 
Sundblom, Bergstrom and Elinder, 2015). These previous studies explored issues for adults with intellectual disabilities who were currently participating in weight management services. However, adults with intellectual disabilities in this study who wanted to manage their weight experienced many barriers to accessing healthy lifestyle information and to weight management services in the first place and they expressed their frustration with all these barriers. Overcoming barriers to accessing healthy lifestyle information and to weight management services may lead to reduced feelings of frustration, increased feelings of motivation and longer-term weight management and health improvements for this population (Bennett and Cunningham, 2014). This study's findings suggest that when individuals with intellectual disabilities received support they were more likely to access and utilise weight management services and some achieved their weight loss goals.

This study's participants valued being with others who had the same interests as them - such as the support of others in weight management groups with similar weight loss goals and or the support of others with the same interests to take them to activities that they enjoyed such as attending football or rugby matches. Other studies have highlighted the importance of peer support, friendships and social support systems for people with intellectual disabilities to help them live well and promote their quality of life (McVilley et al., 2006; Hamilton et al., 2017). This finding suggests a wider `buddying’ support system or scheme for weight management (and for the promotion of their general health and wellbeing) may be beneficial for adults with intellectual disabilities and this requires further exploration.

The study's overall findings support other studies' arguments for greater collaborative working involving health care practitioners, service commissioners, service providers, people with intellectual disabilities, their carers and support workers (Taggart, 2014). Such collaborative working may lead to practical action that may, in turn, contribute to reductions 
in some of the inequities in health service provision and health inequalities experienced by adults with intellectual disabilities (Taggart, 2014).

\section{Issues encountered when conducting research involving people with intellectual disabilities}

Some of the challenges described by other researchers who have conducted research involving this population (Booth and Booth, 1996; Nind, 2008; Kaehne and O'Connell, 2010; Nicholson et al., 2013) were not encountered in this study. Strategies adopted by this study included the early involvement of self-advocates in research proposals and the research design, the use of a self-advocacy group to assist with recruitment of participants, co-produced research materials, the use of a pre-existing forum and venue for focus groups, the use of trained facilitators who have experience of working with this population, the setting of ground rules in the focus groups, having a flexible approach to the research, and learning from people with intellectual disabilities in line with `experts by experience’ principles (Care Quality Commission, 2018). However, not every participant engaged in the focus groups: two participants chose not to hand back either a completed questionnaire or a completed worksheet to the lead researcher and a further three participants chose only to complete and hand back a completed worksheet. This suggests that some participants may have required further support to enable their full participation in the study, and or a lack of their sustained interest in the research, and or a reluctance or inability to share their views and experiences. Also, the fact that more worksheets than questionnaires were completed and handed back implies that participants may have preferred the shorter (one size of A4) format of the worksheet to the questionnaire format. Furthermore, the 15 minute group discussion involving 19 participants held at the end of the focus groups was a sizable group and this could have limited full participation. However, the group discussion did provide a useful vehicle for bringing together participants from each of the four focus groups and enabled a wider sharing and discussion of participants' views and experiences with their peers, carers and support workers. Table 1 summarises the 
principles of inclusive research and the strategies used during this study to reduce or mitigate challenges described by other researchers. 
Table 1: Applying the principles of inclusive research

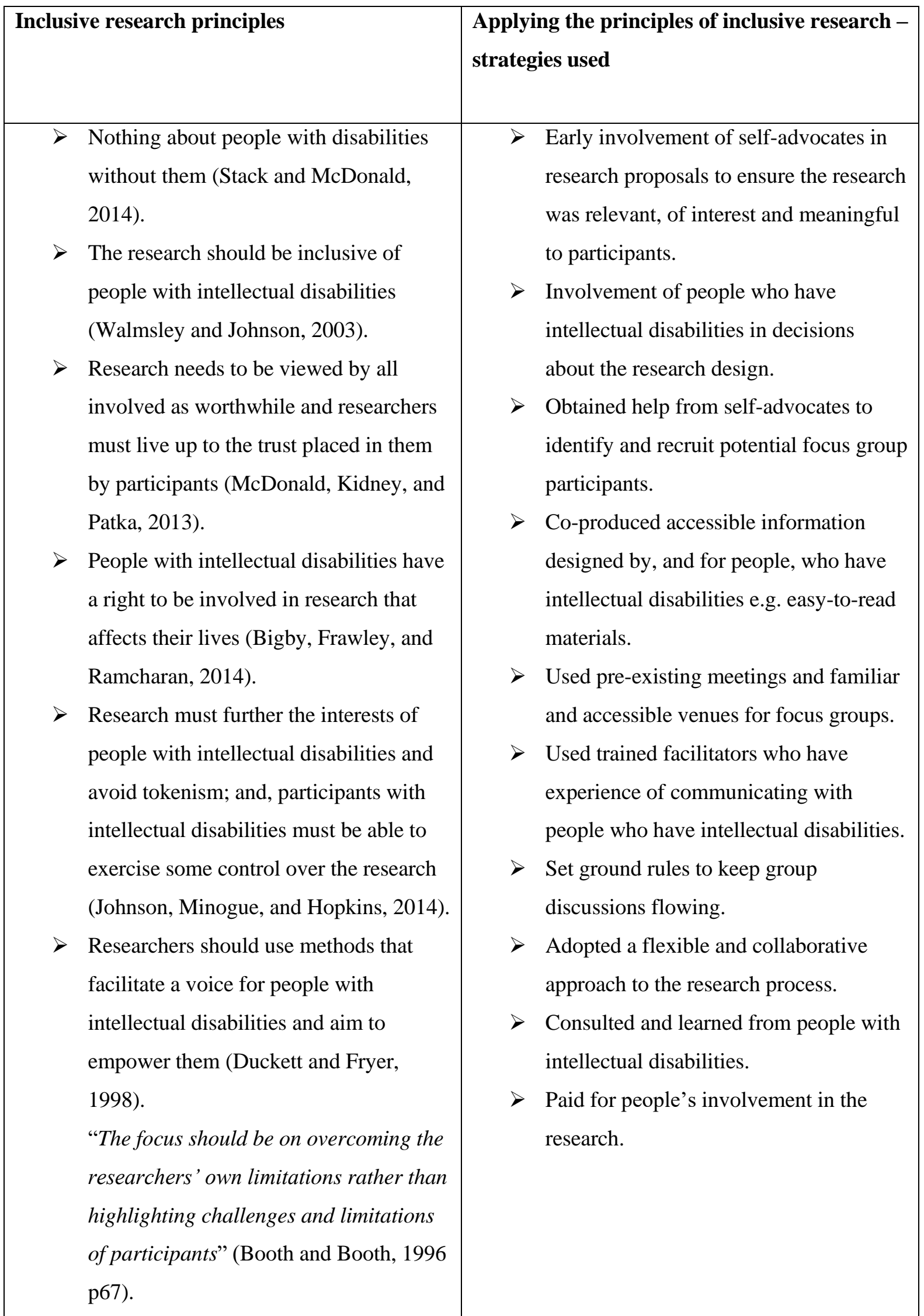




\section{Strengths and limitations of the research}

A strength of this study is that it is, to the best of our knowledge, the first co-produced qualitative study involving adults with intellectual disabilities to explore their views and experiences of barriers and facilitators to eating well, living well and weight management. The study entailed collaboration between the lead researcher and adults with intellectual disabilities to generate new knowledge that neither could produce alone (Bigby, Frawley and Ramcharan, 2014). A strength of such an approach is that it aims to maintain "the integrity and authenticity of the contributions made by people with learning disability" (Bigby, Frawley and Ramcharan, 2014 p9).

The study was not restricted to adults with intellectual disabilities who were obese or overweight, or adults with intellectual disabilities accessing weight management services. The study therefore captured the views of some adults with intellectual disabilities who were not obese or overweight and highlighted the challenges they faced in remaining so, as well as the problems of some who identified themselves as overweight or obese. However, there are limitations with this study. The participants included a small sample of self-selected adults with mild-to-moderate intellectual disabilities who were all involved in the same regional forum. There were twice as many males as females and there were no young adults or elderly adults with intellectual disabilities.

There were limitations with the data collection. The focus groups were not audio - or visually - recorded on the actual day of proceedings due to the venue's size and noise restrictions. However, easy-read questionnaires and worksheets were used to collect data from the four focus groups and notes were made of the wider group discussion by the lead researcher. Information on participants' gender, age or level of support required was not gathered from the participants' questionnaires, worksheets or the group discussion or cross- 
referenced with consent information provided by participants and not all participants chose to complete and hand in questionnaires or worksheets, and it was therefore not possible to attribute quotes by age, gender or level of support required. Findings may therefore not be generalizable to all adults with intellectual disabilities. The presence of peers, carers, support workers, facilitators or researchers may have led to a positive response bias (Ottmann and Crosbie, 2013). Whilst the provision of a one-off fee may have influenced participation, it is important to pay people for sharing their valuable time and experiences and this co-produced study's findings do provide an insight into the complexity of challenges faced by some adults with intellectual disabilities.

\section{Recommendations}

This study provides recommendations for further co-produced research and further action. There is a need for more collaborative and co-produced research to develop better and more accessible healthy lifestyle information for this population. This finding is supported by other literature (Taggart and Cousins, 2014). This study, and other studies' findings (Emerson and Hatton, 2007; Hamilton et al., 2017), recommend the need for further research to investigate the wider socio-economic and environmental barriers experienced by this population, rather than a reliance on clinical weight management interventions which focus on an individual's responsibility for behaviour change to achieve short-term weight loss goals. Participants in this study highlighted the value of peer support systems or schemes - a finding which is similarly supported by other literature (McVilley et al., 2006; Hamilton et al., 2017). Further research is therefore needed to develop and evaluate such schemes for this population. Further research is also needed to explore weight management issues for different sub-group populations of people with intellectual disability as people with intellectual disabilities are not a homogeneous group (Emerson and Hatton, 2014). The inclusivity of existing commercial and non-commercial weight management services (including referral processes, access and 
delivery issues) for adults with intellectual (and physical) disabilities may also be explored through further co-produced research.

In terms of practice recommendations, this study's findings imply a training need for carers and support workers on how to support people with intellectual disabilities to eat and live well and why this is important, and a need for the greater involvement of carers and support workers in weight management interventions. This recommendation is supported by previous studies' findings (Chapman, Craven and Chadwick, 2005; Spanos et al., 2013b). This study also recommends the need for co-produced research and improvements in practice to weight management services and interventions generally for this population. These research and practice recommendations arising from this focus group study are summarised in Table 2 .

\section{Conclusions}

This study has involved adults with intellectual disabilities in co-produced research to explore their views and experiences of barriers and facilitators to eating well, living well and weight management. Barriers identified included problems accessing routine caring support; a lack of clear and accessible healthy lifestyle information; unmet training needs for carers and support workers; personal income restrictions; and external barriers such as inaccessible services and the widespread marketing and availability of less healthy foodstuffs. The study found that solutions to participants' identified barriers and their associated frustrations are required. Practical solutions identified by participants included: provision of clear and accessible healthy lifestyle information, reasonable adjustments to services and associated activities so they are more accessible to this population, training for carers and support workers, wider 'buddying' support systems or schemes, and more collaborative working involving this population, their carers, support workers, health care practitioners, service commissioners and service providers. The study's findings also imply that adults with 
intellectual disabilities experience inequities in referrals and access to non-commercial weight management interventions and services. This requires further investigation given the high prevalence of obesity in this population and the associated health risks.

\section{Acknowledgements}

Thank you to all the participants who openly shared their views and experiences, to the carers and support workers for supporting them, to the co-producers of the research, the facilitators, and to the self-advocacy group and Regional Forum. 
Table 2: Research and practice recommendations arising from focus groups findings

\section{Research recommendations}

1. Further research to explore issues for intellectual disabilities' sub-group populations (by age, sex, ethnicity, type and level of intellectual [and physical] disability, levels of support required, and by weight status).

2. Collaborative research to develop better and more accessible healthy lifestyle information for people with intellectual disabilities.

3. Research into the wider external socio-economic and environmental barriers that affect the health and wellbeing of people who have intellectual disabilities.

4. The development and evaluation of 'buddying' support systems or schemes for this population.

5. Further co-produced research involving adults with intellectual disabilities to explore the inclusivity of existing commercial and non-commercial weight management services (including referral and access issues) for adults with intellectual (and physical) disabilities.

\section{Practice recommendations}

6. Training for carers and support workers on how to support people with intellectual disabilities to eat well and live well and why this is important.

7. The greater involvement of carers and support workers in weight management interventions to support people who have intellectual disabilities.

8. Reasonable adjustments to existing mainstream weight management and healthy lifestyle activities and services so they are accessible to people who have intellectual (and physical) disabilities.

9. Improvements in referrals of adults who have intellectual (and physical) disabilities to mainstream weight management services - including the tailoring of such services to meet the needs of this population. 


\section{References}

Attride-Stirling, J., (2001) Thematic networks: an analytical tool for qualitative research. Qualitative Research. 1(3):385-405.

Bennett, A.E., and Cunningham, C., (2014) A qualitative evaluation of a healthy cookery course in Ireland designed for adults with mild to moderate intellectual disability. Journal of Intellectual Disability.6(3):270-281.

Bigby, C., Frawley, P., and Ramcharan, P., (2014) Conceptualizing inclusive research with people with learning disability. Journal of Applied Research in Intellectual Disabilities. 27:312.

Booth, T., and Booth W., (1996) Sounds of silence: narrative research with inarticulate subject. Disability \& Society. 11(1):67.

Braun, V., Clarke, V., (2006) Using thematic analysis in psychology. Qualitative Research in Psychology. 3:77-101.

Brown, M., Taggart, L., Karatzias, T., Truesdale, M., Walley, R., Northway, R., Macrae, S., Carey, M., and Davies, M., (2017) Improving diabetes care for people with learning disabilities: a qualitative study exploring the perceptions and experiences of professionals in diabetes and learning disability services. Journal of Intellectual Disability Research. 61(5):435-449.

Care Quality Commission (2018) Experts by Experience Procurement. https://www.theguardian.com/social-care-network/2013/mar/21/service-users-watchdoginspection-team (accessed 16.02.18)

Cartwright L., Reid, M., Hammersley, R., and Walley, R.M., (2017) Barriers to increasing the physical activity of people with intellectual disabilities. British Journal of Learning Disabilities. 45(1):56-63.

Chapman M.J., Craven M.J. \& Chadwick D.D. (2005) Fighting fit? An evaluation of health practitioner input to improve healthy living and reduce obesity for adults with learning disabilities. Journal of Intellectual Disabilities. 9(2):131-144.

Chapman, R., (2013) An exploration of the self-advocacy support role through collaborative research: 'there should never be a them and us'. Journal of Applied Research in Intellectual Disabilities. 27: 44-53.

Collins, H.M., and Evans, R.J., (2002) The third wave of science studies: studies of expertise and experience. Social Studies of Science. 32(2):235-96.

Craig, D., and Bigby, C., (2015) Critical realism in social work research: examining participation of people with learning disability. Australian Social Work. 68(3):309-323.

Doherty A.J., Jones S.P, Chauhan U., Gibson J.M.E. (2017) A systematic review of multicomponent weight management interventions for adults with intellectual disabilities. Journal of Applied Research in Intellectual Disabilities. 1-13.

Duckett, P.S., and Fryer, D., (1998) Developing empowering research practices with people who have learning disabilities. Journal of Community \& Applied Social Psychology. 8:57-65. 
Emerson, E., (2003) Mothers of children and adolescents with learning disability: social and economic situation, mental health status, and the self-assessed social and psychological impact of the child's difficulties. Journal of Intellectual Disability Research. 47: 385-399.

Emerson, E., and Hatton, C., (2007) Socio-economic disadvantage, social participation and networks and the self-rated health of English men and women with mild and moderate intellectual disabilities: a cross sectional survey. European Journal of Public Health. 18(1):31-37.

Emerson, E., and Hatton, C., (2014) Health Inequalities and people with learning disabilities. Cambridge Medicine. Cambridge University Press.

Fraser, M., and Fraser, A., (2001) Are people with learning disabilities able to contribute to focus groups on health promotion? Journal of Advanced Nursing. 33(2):225-233.

Frey, G.C., Buchanan, A.M., and Rosser Sandt, D.D., (2005) "I'd Rather Watch TV": An examination of physical activity in adults with mental retardation. Mental Retardation. 43(4):241-254.

Gates, B., and Waight, M. (2007) Reflections on conducting focus groups with people with learning disabilities: theoretical and practical issues. Journal of Research in Nursing. 12:111126.

Hamilton, L.G., Mesa, S., Hayward, E., Price, R., and Bright, G., (2017) 'There's a lot of places I'd like to go and things I'd like to do': the daily living experiences of adults with mild to moderate intellectual disabilities during a time of personalised social care reform in the United Kingdom. Disability \& Society. January 2017. 1-21.

Hatton, C., Roberts, H., and Baines, S., (2011) Reasonable Adjustments for People with Learning Disabilities in England: A National Survey of NHS Trusts. Improving Health and Lives: Learning Disabilities Observatory, Durham.

Horvat, M., Franklin, C., (2001) The effects of the environment on physical activity patterns of children with mental retardation. Research Q Exercise Sport. 72: 189-195.

Johnson, K., Minogue, G., and Hopkins, R., (2014) Inclusive research: making a difference to policy and legislation. Journal of Applied Research in Intellectual Disabilities. 27:76-84.

Kaehne, A., and O'Connell, C., (2010) Focus groups with people with learning disabilities. Journal of Intellectual Disabilities. 14(2):133-145.

Matthews, L., Penpraze, V., Boyle, S., Hankey, C.R., Macmillan, S., Miller, S., Murray, H., Pert, C., Spanos, D., Robinson, N., and Melville, C.A., (2011) Agreement of accelerometer and a physical activity questionnaire in adults with intellectual disabilities. Preventative Medicine, 5: 361-264.

McDonald, K.E., Kidney, C.A., and Patka, M., (2013) 'You need to let your voice be heard': research participants' views on research. Journal of Intellectual Disability Research. 57:216225.

McGuire, B.E., Daly, P., and Smyth, F., (2007) Lifestyle and health behaviours of adults with an intellectual disability. Journal of Intellectual Disability Research, 51: 497-510.

McVilly, K.R., Stancliffe, R.J., Parmenter, T.R., and Burton-Smith, R.M., (2006) I get by with a little help from my friends: adults with intellectual disabilities discuss loneliness. Journal of Applied Research in Intellectual Disabilities. 19(2):191-203. 
Melville C. A., Finleyson J., Cooper S., Allan L., Robinson N., Burns E. et al. (2005) Enhancing primary healthcare services for adults with intellectual disabilities. Journal of Intellectual Disability Research. 49: 190-8.

Melville, C.A., Hamilton, S., Hankey, C.R., Miller, S., Boyle, S., (2007) The prevalence and determinants of obesity in adults with intellectual disabilities. Obesity Reviews. 8:223-230.

Melville, C.A., Cooper, S., Morrison, J., Allan, L., Smiley, E. and Williamson, A., (2008) The prevalence and determinants of obesity in adults with intellectual disabilities. Journal of Applied Research in Intellectual Disabilities, 21: 425-437.

Messent, P.R., and Cooke, C.B., (1998) Physical activity, exercise and health of adults with mild and moderate learning disabilities. British Journal of Learning Disabilities. 26:17-21.

Nelson, P., Tod, A., Cronin de Chavez, A., Powell-Hoyland, V., and Stocks, A., (2013) Warm Well Families: Doncaster Final Report. Project Report. Doncaster, Doncaster, Doncaster Metropolitan Borough Council.

NHS Digital, (2017) Health and Care of People with Learning Disabilities. http://content.digital.nhs.uk/article/7543/Health-and-Care-of-People-with-LearningDisabilities [accessed 07/03/17].

NICE, (National Institute for Health and Care Excellence) Clinical Guideline 189 (2014b) Obesity: Identification, Assessment and Management of Overweight and Obesity in Children, Young People and Adults. Issued November 2014. http://www.nice.org.uk/guidance/cg189 [accessed 07/10/15].

Nicholson, L., Colyer, M., and Cooper, S.A., (2013) Recruitment to intellectual disability research: a qualitative study. Journal of Intellectual Disability Research. 57(7):647-656.

Nind, M., (2008) Conducting qualitative research with people with learning, communication and other disabilities: methodological challenges. ESRC National Centre for Research Methods. NCRM/012.

Nind, M. and Vinha, H., (2012) Doing research inclusively: bridges to multiple possibilities in inclusive research. British Journal of Learning Disabilities. 42:102-109.

Ottmann, G., and Crosbie, J., (2013) Mixed method approaches in open-ended, qualitative, exploratory research involving people with intellectual disabilities: a comparative methods study. Journal of Intellectual Disabilities. 17(3):182-197.

Pelloboer-Gunnick, H.A., Van Oorsouw, W.M.W.J., Van Weeghel, J., Embregts, P.J.C.M., (2017) Mainstream health professionals' stigmatising attitudes towards people with intellectual disabilities: a systematic review. Journal of Intellectual Disability Research. 61(5):411-434.

Public Health England, (2015) Obesity and Health. www.noo.org.uk/NOO_about_obesity/obesity_and_health [accessed 16.07.15].

Rimmer, J.H., and Yamaki, K., (2006) Obesity and intellectual disability. Mental Retardation and Developmental Disabilities Research Reviews, 12:22-27.

Roller, M.R., and Lavrakas, P.J., (2015) Limitations of transcripts: is it time to talk about the elephant in the room'. In Applied Qualitative Research Design: A Total Quality Framework Approach. New York. Guildford Press. 
Simons, B., and Watson, D., (2015) From individualism to co-construction and back again: rethinking research methodology for children with profound and multiple learning disabilities. Child Care in Practice. 21(1):50-66.

Spanos, D., Melville, C.A., and Hankey, C.R., (2013a) Weight management interventions in adults with intellectual disabilities and obesity: A systematic review of the evidence.

Nutrition Journal, 12: 132.

Spanos, D., Hankey, C., R., Boyle, S., Koshy, P., Macmillan, S., Matthews, L., Miller, S., Penpraze, V., Pert, C., Robinson, N., Melville, C.A., (2013b) Carers' perspectives of a weight loss intervention for adults with intellectual disabilities and obesity: A qualitative study. Journal of Intellectual Disability Research, 57(1): 90-102.

Spanos, D., Hankey, C., Boyle, S., and Melville, C., (2014) Comparing the effectiveness of a multi-component weight loss intervention in adults with and without intellectual disabilities. Journal of Human Nutrition \& Dietetics, 27(1): 22-29.

Stack, E., and McDonald, K.E., (2014) Nothing about us without us: does action research in developmental disabilities research measure up? Journal of Policy and Practice in Intellectual Disabilities. 11(2):83-91.

Sundblom, E., Bergstrom, H., and Elinder, L.S., (2015) Understanding the implementation process of a multi-component health promotion intervention for adults with intellectual disabilities in Sweden. Journal of Applied Research in Intellectual Disabilities, 28:296-308.

Taggart, L., (2014) Health promotion and healthcare for people with intellectual disabilities. Journal of Applied Research in Intellectual Disabilities. 27:289-290.

Taggart, L., and Cousins, W., (2014) Health Promotion for People with Intellectual and Developmental Disabilities. McGraw Hill Education. Open University Press.

Walmsley, J., (2001) Normalisation, emancipatory research and inclusive research in learning disability. Disability \& Society. 16(2):187-205.

Walmsley, J., and Johnson, K., (2003) Inclusive research with people with intellectual disabilities: past, present and futures. London, Jessica Kingsley. 


\section{Study Topic Guide}

Focus groups involving adults with learning disabilities and their carers, or people who routinely support them

Title of project: Finding out what people think about eating well and living well

Question 1

\begin{tabular}{|c|c|}
\hline Question & Answer \\
\hline $\begin{array}{c}\text { Do you think you are } \\
\text { healthy? Yes or No }\end{array}$ \\
\hline $\begin{array}{c}\text { If your answer is yes. } \\
\text { What do you do to keep } \\
\text { healthy? }\end{array}$ \\
\hline $\begin{array}{c}\text { If your answer is no. } \\
\text { Why don't you think you } \\
\text { are healthy? }\end{array}$
\end{tabular}

\section{Question 2}

\begin{tabular}{|c|c|c|}
\hline & Question & Answer \\
\hline 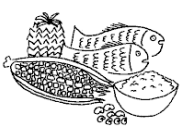 & Do you want to eat well? & \\
\hline 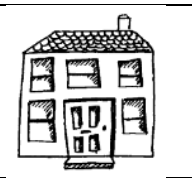 & Do you want to live well? & \\
\hline
\end{tabular}




\section{Question 3}

\begin{tabular}{|c|c|c|}
\hline & Question & Answer \\
\hline 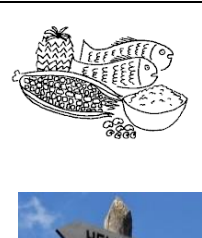 & $\begin{array}{c}\text { Is there anything which } \\
\text { helps you eat well, if you } \\
\text { want to? }\end{array}$ & \\
\hline & $\begin{array}{c}\text { If your answer is yes. } \\
\text { What helps? }\end{array}$ & \\
\hline 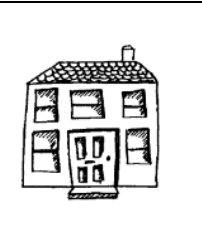 & $\begin{array}{c}\text { Is there anything which } \\
\text { helps you live well, if you } \\
\text { want to? }\end{array}$ & \\
\hline & $\begin{array}{c}\text { If your answer is yes. } \\
\text { What helps? }\end{array}$ & \\
\hline
\end{tabular}

\section{Question 4}

\begin{tabular}{|c|c|c|}
\hline Question & Answer \\
\hline & $\begin{array}{c}\text { Is there anything which } \\
\text { stops you from eating } \\
\text { well, if you want to? }\end{array}$ \\
\hline $\begin{array}{c}\text { If your answer is yes, } \\
\text { what sort of things? }\end{array}$ & \\
\hline
\end{tabular}




\begin{tabular}{|c|c|}
\hline & $\begin{array}{c}\text { Is there anything which } \\
\text { stops you from living } \\
\text { well, if you want to? }\end{array}$ \\
\hline & $\begin{array}{c}\text { If your answer is yes, } \\
\text { what sort of things? }\end{array}$ \\
\hline
\end{tabular}

\section{Question 5}

\begin{tabular}{|c|c|}
\hline Question & Answer \\
\hline Do you have any \\
concerns about your \\
health?
\end{tabular}

\section{Question 6}

\begin{tabular}{|c|c|} 
Question & Answer \\
Do you have any \\
concerns about your \\
weight?
\end{tabular}




\section{Question 7}

\begin{tabular}{|c|c|c|}
\hline & Question & Answer \\
\hline "Sis & $\begin{array}{l}\text { Have you ever been } \\
\text { referred to any weight } \\
\text { loss services? Like } \\
\text { slimming world, a } \\
\text { dietician, exercise } \\
\text { classes? }\end{array}$ & \\
\hline & If you answer is yes:- & \\
\hline Slimming & $\begin{array}{l}\text { What types of weight } \\
\text { loss services have you } \\
\text { been referred to? } \\
\text { (prompt - dietician, } \\
\text { exercise classes, } \\
\text { slimming World). }\end{array}$ & \\
\hline $\begin{array}{l}\leftarrow \text { Problems } \\
\text { Solutions } \rightarrow\end{array}$ & $\begin{array}{c}\text { Did you go to these } \\
\text { services? }\end{array}$ & \\
\hline & $\begin{array}{l}\text { If not, why did you not } \\
\text { go? }\end{array}$ & \\
\hline & $\begin{array}{c}\text { If you went to these } \\
\text { services, did you find } \\
\text { them helpful or not } \\
\text { helpful? }\end{array}$ & \\
\hline
\end{tabular}




\begin{tabular}{|c|c|c|}
\hline & $\begin{array}{c}\text { If they were helpful, } \\
\text { what helped? }\end{array}$ \\
\hline & $\begin{array}{c}\text { If they were not helpful, } \\
\text { what did not help? }\end{array}$ \\
\hline
\end{tabular}

Question 8

\begin{tabular}{|c|c|c|}
\hline & Question & Answer \\
\hline & $\begin{array}{c}\text { What do you think } \\
\text { can be done to } \\
\text { improve the health } \\
\text { and wellbeing of } \\
\text { people with learning } \\
\text { disabilities? }\end{array}$ \\
\hline
\end{tabular}




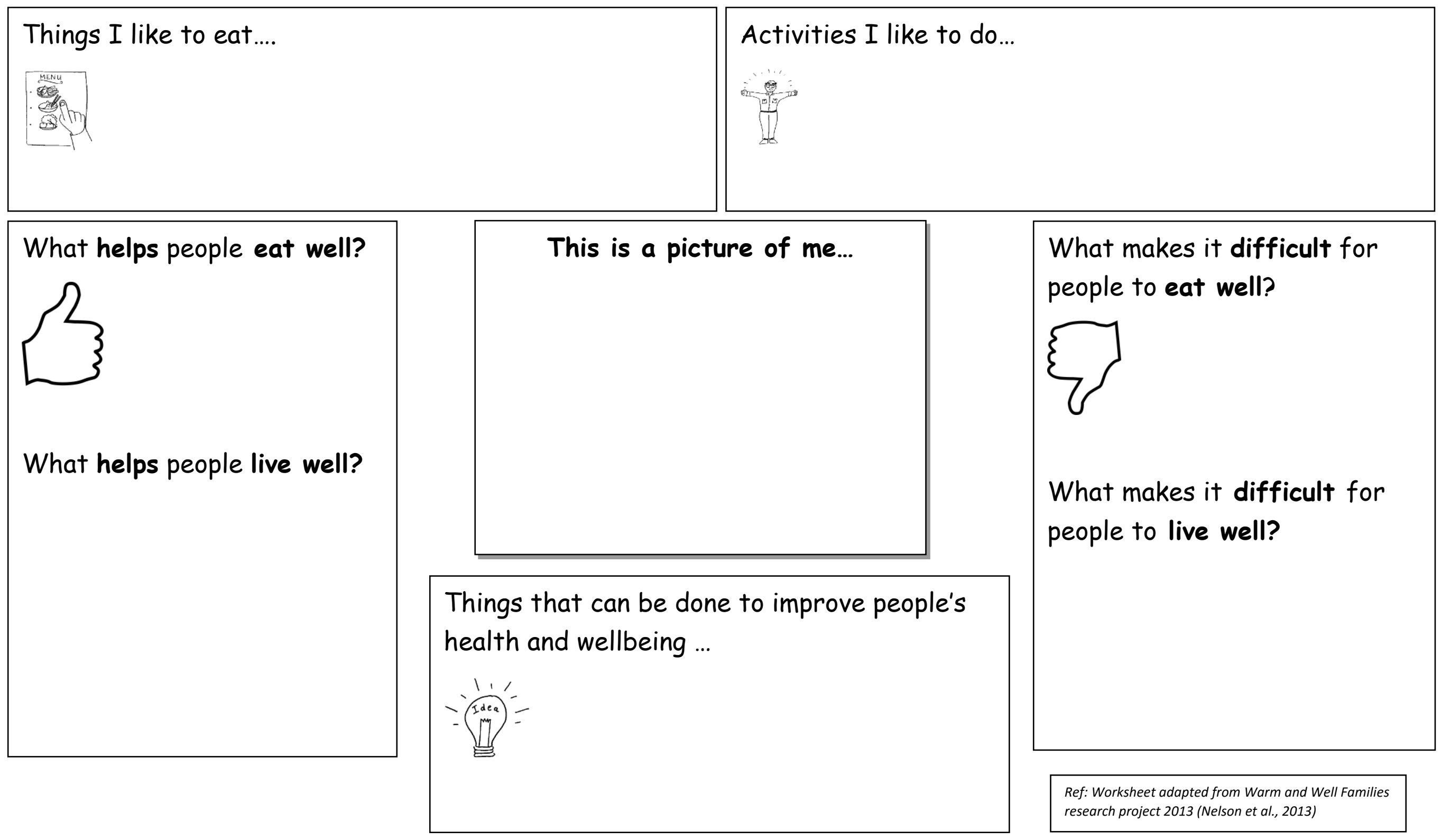

